\title{
EMISSION SPECTRA OF LUMINOUS BACTERIA
}

\author{
by \\ A. SPRUIT-VAN DER BURG \\ Biophysical Research Group under the direction of A. J. KLUYvRR, Delft and of \\ J. M. W. MILATz, Utrecht (Netherlands)
}

\section{INTRODUCTION}

In I936 and I937, EYMERS AND VAN SchouwenBURG ${ }^{1,2}$ published their work on the emission spectra of Photobacterium phosphoreum and two other species of luminous bacteria as well as observations on the spectra of some chemoluminescent reactions. In the course of our own investigations we became aware of the fact that a considerable error may be caused by the absorption of emitted light by the emitting material itself. It is well known that many if not all organisms contain compounds exhibiting selective absorption in the visible region. As such may be mentioned riboflavin and the cytochromes.

The error due to absorption is composed of two factors. One of these must be attributed to absorption of the light by the emitting bacterium itself, the other to repeated absorption by surrounding cells. As regards the error caused by the absorbing compounds within the emitting cell, a rough calculation indicates that this is negligible if one may assume that the coloured compounds are distributed homogeneously over the cell. The second of these two causes of error can be made negligible by using very dilute suspensions as will be shown below. This method has the disadvantage that the light intensity to be measured is small, so that long exposures are needed. Still this is the only way of avoiding the application of corrections to the measured spectrum. Such corrections cannot be made accurately, as we are dealing here with a combination of absorption and scattering. As we will show, EYMERS AND VAN SCHOUwENBURG did not pay sufficient attention to these sources of error which have rather seriously affected their results.

\section{EXPERIMENTAL METHODS}

The organisms used are kept in the culture collection of the Biophysical Research Group under the following names: Photobacterium phosphoreum, Ph. splendidum, Ph. fischeri. The bacteria were cultivated in liquid media of the following composition:

$P h$. phosphoreum in: peptone $2 \%$, sodium nitrate $1 \%$, sodium chloride $2 \%, P h$. fischeri in: peptone $1 \%$. glycerol $1 \%$, sodium chloride $3 \%$ to which small pieces of limestones were added. Both species were cultivated in aeration flasks. $P h$. splendidum was grown in flasks with shallow layers of a medium containing: yeast autolysate 1 : 10 , sodium nitrate $1 \%$, sodium chloride $2 \%$. After about twenty hours when maximum luminescence had developed the bacteria were separated by centrifuging, washed with $3 \%$ sodium chloride solution, and suspended in $0.125 M$ phosphate buffer containing in addition: in the case of $P h$. phosphoreum and $P h$. splendidum glucose $3 \%$. sodium nitrate $1 \%$, sodium chloride $2 \%$, in the case of $P h$. fischeri glucose $3 \%$, sodium chloride $3 \%$.

The suspensions were placed before the slit of the spectrograph in a LEYBOLD glass box with a 
depth of $1 / 2$ or $1 \mathrm{~cm}$, the back wall of which had been painted black to avoid an increase in light path by reflection. During the exposure air was bubbled through the bacterial suspension.

The emission spectra were obtained by a photographic method. Two spectrographs were used, viz., a Fuess glass spectrograph $\mathrm{f} / \mathrm{g}$ in which another lens had been placed behind the camera objective in order to bring the opening to $\mathrm{f} / 4.5$ appr. The other was a VAN HEzL spectrograph $\mathrm{f} / 2$ with a prism filled with ethyl cinnamate. With this instrument special precaution had to be taken to keep the temperature of the prism constant during the long exposures, $P h$. phosphoreum and $P h$. splendidum were photographed with both instruments, $P h$. fischeri with the $\mathrm{f} / 2$ instrument only.

The photographic material was Agfa Isopan SS, pre-illuminated with red light to give a density of $6 \%$ after development. By this treatment threshold difficulties are overcome, thus increasing the sensitivity for small light intensities.

In order to obtain density marks, spectra were photographed for comparison on the same plates, from a calibrated band lamp with the aid of a step slit. The actual emission spectra were also photographed through a step slit. In this way on each plate several spectra of the same bacterial suspension were obtained. The conversion of transmission into intensity of the spectra was carried out according to the method described more in detail by EYMERS AND VAN SchouwhNBURG ${ }^{1}$ (see also references). The spectra reproduced in the following section are averages of several measurements.

\section{INFLUENCE OF DENSITY OF SUSPENSIONS ON THE EMISSION SPECTRA}

This is illustrated in Fig. I. Curve B was obtained with a density of $8 \mu \mathrm{l} / \mathrm{ml}$ wet bacteria of $P h$. phosphoreum per $\mathrm{ml}$ liquid and with a vessel with black back wall, curve $\mathrm{C}$ with a density of $40 \mu \mathrm{l} / \mathrm{ml}$ and a vessel with white back wall. The difference in the two spectra is caused by the increased absorption in the suspension with the highest density. This absorption is especially marked in the blue region. Above $\lambda=560 \mathrm{~m} \mu$ the two curves are in fact identical. Curve $A$ was taken at a density of $2 \mu \mathrm{l} / \mathrm{ml}$. The difference with curve $B$ is only slight, and amounts to $10-15 \%$ for wave-lengths below $460 \mathrm{~m} \mu$. As in the case of curve $B$ the density is four times that of curve $A$, the absorption present in curve $B$ must be more than four times that of curve $A$. We conclude that the

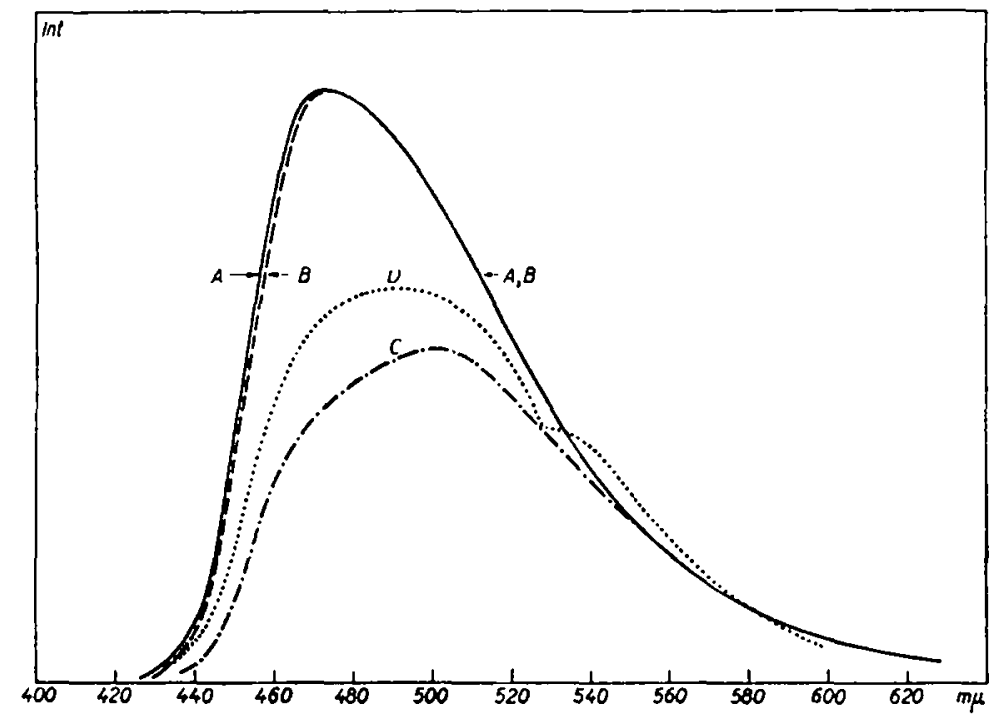

Fig. I. Influence of the density upon the emission spectrum of Ph. phosphoreum

intensity drop of Io- $15 \%$ corresponds to more than three times the absorption still present in curve A. It follows that this absorption must be less than $3-5 \%$. As the 
accuracy of the measurement is about $3 \%$, the curve A may be considered to give the most accurate representation of the emission spectrum of $P h$. phosphoreum obtainable with the method employed". In the same way we found that spectra of $P h$. splendidum at densities 6 and $\mathrm{I} 8 \mu \mathrm{l} / \mathrm{ml}$ and a depth of $0.5 \mathrm{~cm}$ were identical within the experimental error, and of $P h$. fischeri at densities 5 and $15 \mu 1 / \mathrm{ml}$. Consequently the curves given in Fig. 2 apply to these densities.

Curve $\mathrm{D}$ of Fig. I is the spectrum published previously by EYMERS AND VAN SCHOUWENBURG (l.c.). They used a vessel which was painted completely white with the exception of the wall facing the spectrograph. From the data given in their paper it may be concluded that they have used a density of approximately $20 \mu \mathrm{l} / \mathrm{ml}$. Their curve fits in between our curves $B$ and $C$, as can be expected. The secondary maximum in curve $\mathrm{D}$ at approximately $540 \mathrm{~m} \mu$ is probably due to an irregularity in the photo-. graphic material.

\section{RESULTS AND DISCUSSION}

The final results of our measurements are given in Fig. 2. The wave-lengths of maximum emission are approximately: Ph. phosphoreum $472 \mathrm{~m} \mu$. Ph. splendidum $489 \mathrm{~m} \mu$ and $P h$. fischeri $496 \mathrm{~m} \mu$. For comparison the spectrum of the fungus Armillaria mellea, with maximum at $526 \mathrm{~m} \mu$, published previously ${ }^{4}$ and discussed in detail elsewhere ${ }^{5}$ is also included. There is no doubt that the spectra of the luminescent organisms investigated are different. Apparently the conclusion of EyMERS AND VAN SCHOUWENBURG 2 that the spectra of $P h$. phosphoreum and $P h$. splendidum are the same is not correct.

Finally we wish to make some remarks regarding the attempted analysis of emission

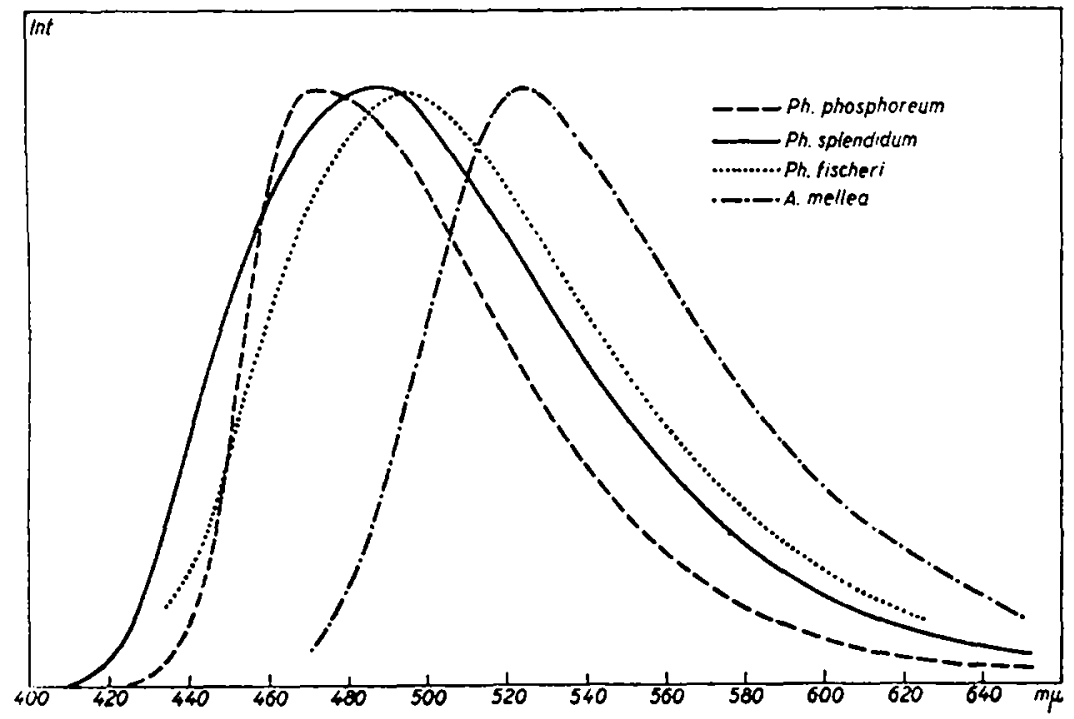

Fig. 2. Emission spectra of luminous organisms

spectra by EYMERS AND VAN SchouWENBURG ${ }^{1,2}$. These authors believe to have given evidence that emission spectra of chemo- and bioluminescent reactions as well as 
fluorescence spectra, plotted versus frequency, could be analysed into a discreet number of symmetrical curves, each representing a broadened, so-called fundamental frequency. Considering the fact that emission spectra of large molecules are superpositions of vibrational and rotational bands, the position of which in the spectrum is determined by the magnitude of the corresponding electronic transition, there is little reason to expect the same frequencies to occur in the spectra of different sources. The spectra of bioluminescent reactions published in this paper give no support to this hypothesis of Eymers and Van Schouwenburg. It is to be regretted that this idea still receives attention in the literature ${ }^{0, ?}$.

Owing to various circumstances this work, the experimental part of which was carried out during I943, could not be published until now.

\section{SUMMARY}

Emission spectra have been determined of three species of luminous bacteria. It is shown that in this determination special attention has to be paid to the absorption of the emitted light by the bacterial suspensions themselves.

\section{RESUME}

L'auteur a déterminé les spectres d'émission de trois espèces de bactéries lumineuses. Il a montré q'il est nécessaire de tenir compte de l'absorption de la lumiêre émise par les suspensions bactériennes.

\section{ZUSAMMENFASSUNG}

Der Verfasser hat die Emissionsspektren von drei Arten von Leuchtbakterien bestimmt. Es erwies sich hierbei als notwendig, die A bsorption des emittierten Lichtes durch die Bakteriensuspensionen selbst besonders $\mathrm{zu}$ berucksichtigen.

\section{REFERENCES}

1 J. G. EYmers and K. L. VAN SchouWenburg, Enzymologia, i (1936) 107.

2 J. G. Eymers and K. L. VAN Schouwenburg, ibid., 3 (I937) 235.

- L. S. Ornstein, J. W. Moll, and H. C. Burger, Obiektive Spektralphotometrie, Samml. Vieweg. Berlin 1932.

4 A. VAN DRR BURG, Thesis, Utrecht 1943.

- E. C. Wassink AND A. SPRUit-VAN DER BURG, in preparation.

- E. N. Harvey, Living Light, Philadelphia I94I.

? F. H. Johnson, Advances in Enzymology, 7 (1947) 215. 